\title{
Generation from Multiple Sclerosis Patients of Long- Term T-Cell Clones that are Activated by both Human Coronavirus and Myelin Antigens
}

\author{
${ }^{1}$ ANNIE BOUCHER, ${ }^{1}$ FRANÇOIS DENIS, ${ }^{2}$ PIERRE DUQUETTE, AND \\ ${ }^{1}$ PIERRE J. TALBOT \\ 'Human Health Research Center, INRS-Institut Armand-Frappier, Université du Québec, Laval, \\ Québec, CANADA H7V 1B7; ${ }^{2}$ MS Clinic, Notre-Dame Hospital, Montréal, Québec, CANADA \\ $H 2 L 4 K$
}

\section{INTRODUCTION}

Multiple sclerosis (MS) is a chronic central nervous system (CNS) disorder characterized by inflammation and myelin destruction involving autoreactive lymphocytes. While precise disease etiology is still unknown, it appears to be multifactorial, involving both genetic (such as HLA haplotype) and environmental factors (Sadvonick et al. 1993, Ebers et al. 1993). Various microbial infections have been proposed to be associated with triggering the pathology, but no conclusive evidence has been drawn so far.

Human coronaviruses $(\mathrm{HCoV})$, of which two serotypes, OC43 and 229E are known, cause 10 to $35 \%$ of common colds. It has been hypothesized that a natural infection by these ubiquitous respiratory pathogens may lead in some genetically predisposed individuals to a demyelinating pathology. This rests mainly on observations that experimental murine coronavirus infections of genetically susceptible mice and rats induces an MS-like disease: CNS inflammation, cycles of demyelination and remyelination, and activation of myelin-reactive T cells (Lane et al. 1997, Lampert et al. 1973, Weiner et al. 1973, Watanabe et al. 1983). Moreover, accumulating evidence is consistent with the neurotropic and neuroinvasive potential of

The Nidoviruses (Coronaviruses and Arteriviruses).

Edited by Ehud Lavi et al., Kluwer Academic/Plenum Publishers, 2001. 
HCoV: 1) acute and persistent infection of neural cell lines (Collins and Sorensen 1996, Arbour et al. 1999a,b); 2) infection of primary cultures of astrocytes, microglia and cerebral endothelial cells (Cabirac et al. 1995, Bonavia et al. 1997); 3) viral isolation from MS brains (Burks et al. 1980); 4) RT-PCR and in situ hybridization detection of both HCoV-229E and $\mathrm{HCoV}-\mathrm{OC} 43$ in the brain, with a potential association with MS (Murray et al. 1992, Stewart et al. 1992, Arbour et al. 2000). Microbial pathogens might activate MS-associated autoreactive lymphocytes through molecular mimicry in individuals that are genetically predisposed by their HLA haplotype to recognize T-cell epitopes shared between the pathogen and myelin antigens (Oldstone 1997, Wucherpfennig and Strominger 1995, Cantor et al. 1998).

To evaluate whether molecular mimicry between $\mathrm{HCoV}$ and myelin antigens could participate in MS pathogenesis, T-cell cross-reactivity between myelin basic protein (MBP), a putative MS autoantigen and $\mathrm{HCoV}$ 229E was investigated in MS patients (Talbot et al. 1996). Results summarized in Table 1 show that of the numerous peripheral HCoV-229E or MBP-reactive T-cell lines generated, cross-reactivity involved $29 \%$ of Tcell lines from 10 of 16 MS patients and only $1.3 \%$ in 2 of 14 controls $(\mathrm{p}<0.0001)$. To ascertain whether this MS-associated T-cell cross-reactivity could be linked to molecular mimicry, it was mandatory to demonstrate activation of $\mathrm{T}$ cells by both virus and myelin antigens at the single-cell level. Our previous study was also extended to $\mathrm{HCoV}-\mathrm{OC} 43$ and another major myelin component and putative MS autoantigen, proteolipid protein (PLP). Importantly, both MBP and PLP can induce experimental allergic encephalomyelitis (EAE) in rodents (Wekerle et al. 1994). We now describe the methodology used to produce and expand human $\mathrm{T}$ cell clones specific for coronaviral and myelin antigens and the production of cross-reactive $\mathrm{T}$ cell clones.

Table 1. MS-associated cross-reactivity of peripheral T-cell lines for MBP and HCoV-229E (results from Talbot et al. 1996)

\begin{tabular}{lllll}
\hline Donors & $\mathrm{n}$ & \multicolumn{3}{c}{ Cross-reactive T-cell lines } \\
& & Lines & $\mathrm{n}$ & $\%$ \\
\hline MS & 16 & 39 & 10 & 29 \\
Controls & 14 & 2 & 2 & 1.3 \\
\hline
\end{tabular}




\section{MATERIALS AND METHODS}

\subsection{Donors}

Patients diagnosed with either chronic progressive or relapsing remitting MS and who had not received treatment in the last six months were selected at random with prior informed consent and approval of the experimental protocol from institutional ethics committees.

\subsection{Antigens}

Human MBP was prepared from a normal adult brain (Montreal Brain Bank, Douglas Hospital, Verdun, Québec, Canada) as described (Talbot et al. 1996). Chromatography-purified PLP was a kind gift of Dr. Mario Moscarello (Hospital for Sick Children, Toronto, Ontario, Canada). HCoV229E was propagated in the human embryonic lung cell line L132 (ATCC). Viral antigen was prepared from L132 cells infected with HCoV-229E at a MOI of 0.01 at $33^{\circ} \mathrm{C}$ for 43 hours. Cells were lysed and clarified by low speed centrifugation. Before use, infectious virus in the viral antigen preparation $\left(10^{6} \mathrm{TCID}_{50} / \mathrm{mL}\right)$ was inactivated by exposure to ultra-violet light for 20 minutes. $\mathrm{HCoV}-\mathrm{OC} 43$ was propagated in the human rectal carcinoma cell line HRT-18 (ATCC), cultivated and harvested as described above. Control antigen was obtained from parallel cultures. HHV-6 antigens in the form of infected cell lysates were provided by Dr. Louis Flamand, Laval University, Québec, Canada.

\subsection{Generation and Maintenance of T-Cell Clones}

Human blood samples (300-400 mL) were collected from human donors and buffy coat prepared. Peripheral blood lymphocytes (PBL) were separated on Ficoll/Hypaque (Pharmacia) gradients and $1 \times 10^{6}$ cells $/ \mathrm{mL}$ were seeded into 96-well microtiter plates (Talbot et al 1996). After 7 days 
of incubation, $100 \mathrm{U} / \mathrm{mL}$ of interleukin-2 (Hoffman La Roche) was added. At day 12, primary T-cell lines were tested for antigen specificity by a tritiated thymidine incorporation assay. On day 16 , antigen-specific lines were cloned by limiting dilution into 60 -microwell Terazaki plates. A concentration of $5 \times 10^{5}$ autologous irradiated antigen-presenting cells/ well (APC; PBL prepared as described) were added, in the presence of $30 \mu \mathrm{g} / \mathrm{mL}$ of either MBP or PLP $(6 \mu \mathrm{g} / \mathrm{well})$ or a 1/20 final dilution of viral antigens. Interleukin-2 $(50 \mathrm{U} / \mathrm{mL})$ was added to enhance cloning efficiency. After incubation for 10-13 days, each well was checked for cell growth. Cells from plates showing growth in less than $33 \%$ of the wells were selected. Clones were tested for specificity in a proliferation assay but were also expanded in the presence of autologous APC and the specific antigen (MBP, PLP, HCoV-229E or OC43).

\subsection{Antigen-Specific Proliferation Assays}

Proliferation assays were performed by adding $1 \times 10^{4} \mathrm{~T}$ cells per well into 96-well round bottom microtiter plates in the presence of irradiated APC and various antigens in complete culture medium, as described above $(0.1 \mathrm{~mL} /$ well). These specific and control antigens were MBP and PLP (300 $\mu \mathrm{g} /$ well), HCoV-229E and -OC43 viral antigens in infected cell lysates (final dilution of $1 / 2)$, tetanus toxin $(1 \mu \mathrm{g})$, appropriate dilutions of uninfected cell lysates, and serum-free complete culture medium. Cells were incubated for 72 hours, with $1 \mu \mathrm{Ci} /$ well of tritiated-thymidine (Amersham) added for the last 18 hours. Cells were harvested onto glass microfiber filters (Skatron) on a 96-well Skatron model 11050 Micro cell harvester and counted in $2 \mathrm{~mL}$ of Ultimagold scintillation fluid (Packard), using a Canberra Packard Tri-Carb 2200a scintillation counter. The stimulation index was calculated as the ratio of the radioactivity (cpm) incorporated in the presence of specific over control antigen and a ratio above 3.0, with at least $1000 \mathrm{cpm}$ incorporated was considered positive.

\section{RESULTS}

\subsection{Human T-cell clones specific to coronaviral and/or myelin antigens}

From 32 MS patients, the protocol described above led to the generation of $114 \mathrm{~T}$-cell clones responding to viral antigens and $31 \mathrm{~T}$-cell clones activated by myelin antigens, (Table 2). Positive clones showed 
proliferation indices between 3.0 and 19.0. A total of 10 cross-reactive Tcell clones were obtained from 6 patients that were diagnosed with either chronic progressive or relapsing remitting MS.

Table 2. T-cell clones generated from peripheral blood of MS patients

\begin{tabular}{llll}
\hline Donors & \multicolumn{3}{c}{ Total number of T-cell clones generated } \\
\cline { 2 - 4 } & $\begin{array}{l}\mathrm{HCoV} \\
\text { Monospecific }\end{array}$ & $\begin{array}{l}\text { MBP or PLP } \\
\text { Monospecific }\end{array}$ & $\begin{array}{l}\text { Virus-Myelin } \\
\text { Cross-Reactive }\end{array}$ \\
\hline 32 & 114 & 31 & 10 \\
\hline
\end{tabular}

\subsection{Antigen specificity of the cross-reactive T-cell clone}

The antigenic specificities of the ten coronavirus-myelin cross-reactive T-cell clones generated in this study from 6 MS patients are listed in Table 3. Using the same protocol, human herpesvirus type-6 (HHV-6), another virus potentially associated with MS (Challoner et al., 1995), was also tested. Although virus-specific T-cell clones were generated, no HHV-6 and myelin antigen cross-reactive clones were obtained (data not shown).

Table 3. Antigen specificity of cross-reactive T-cell clones

\begin{tabular}{cccccc}
$\begin{array}{c}\text { Clone } \\
\#\end{array}$ & Selecting antigen & $\begin{array}{c}\text { HCoV- } \\
\text { OC43 }\end{array}$ & $\begin{array}{c}\text { HCoV- } \\
229 \mathrm{E}\end{array}$ & PLP & MBP \\
\hline 1 & OC43 & + & - & - & + \\
2 & $229 \mathrm{E}$ & - & + & - & + \\
3 & PLP & - & + & + & - \\
4 & PLP & - & + & + & - \\
5 & MBP & - & + & - & + \\
6 & MBP & - & + & - & + \\
7 & OC43 & + & - & + & + \\
8 & $229 \mathrm{E}$ & - & + & - & + \\
9 & $229 \mathrm{E}$ & - & + & + & + \\
10 & $229 \mathrm{E}$ & - & + & - & + \\
\hline
\end{tabular}

\section{DISCUSSION}

Our results are consistent with clonal T-cell cross-reactivity between either of the two known HCoV serotypes (229E and OC43) and two major myelin antigens and putative MS autoantigens (MBP and PLP). Even though, following Poisson's distribution, a clone is statistically obtained when growth is observed in less then $33 \%$ of seeded wells after cloning by limiting dilution, clonality will be confirmed by molecular techniques as well. 
We were successful in elaborating a protocol to generate and stimulate human T-cell clones after a single blood sampling, despite the technical challenges involved in studying primary $\mathrm{T}$ cells in cultures. Autologous antigen-presenting cells were frozen and later thawed and irradiated when needed. This technique was thus independent of the patient's clinical status or his/her availability for blood samplings. The preservation of the clone's antigenic specificity was of premier concern and we were able to freeze and thaw the clones with no loss of antigenic specificity. Nevertheless, we remain concerned that anergy or apoptosis of $\mathrm{T}$ cells can occur upon repeated stimulations. Our protocol does consider these limitations and allows for the rapid determination of antigenic specificity, in order to preserve the $T$ cells in a state that will allow freezing and later recovery of viable and functional cells. Nevertheless, we are currently making use of techniques such as immortalization of T-cell clones by infection with herpes saimiri virus, as well as T-cell receptor (TCR) reconstitution into hybridomas to allow for the detailed molecular characterization of the putative molecular mimicry mechanism underlying the observed myelincoronavirus cross-reactivities.

Human coronavirus-myelin cross-reactive $\mathrm{T}$-cell clones represent precious tools to understand the triggering of autoimmunity by molecular mimicry in the context of a human disease. How susceptibility is determined could be related to peptide presentation. Indeed, we are in the process of typing the HLA haplotypes of donors to look for any DR2 associations. Molecular mimicry involving viruses represents a very attractive and unifying mechanism that can nicely explain T-cell activation against myelin determinants and the possible involvement of several microbial pathogens in MS. Moreover, cytokines and inflammation could also act as key players by increasing antigen presentation and cellular recruitment. Other viruses could be involved in MS through similar mechanims, although our preliminary study did not reveal T-cell cross-reactivity with HHV-6. Finally, we will search for the presence of coronavirus-myelin crossreactive T-cell clones in the CNS of MS patients and their possible involvement in local pathology.

\section{CONCLUSION}

Our observation that a respiratory virus can activate myelin-reactive $T$ cells would explain the influence of environmental factors in disease etiology and add much credence to the possible role of such viruses in the triggering of MS in individuals that are genetically predisposed to such putative molecular mimicry at the level of T-cell recognition of foreign and 
self-antigens. Activation of such cells could also explain why MS relapses often follow respiratory infections. Moreover, a persistent CNS infection could represent a precipitating factor favoring local inflammation and contribute to recurrent disease exacerbations.

\section{ACKNOWLEDGMENTS}

This work was funded by the Multiple Sclerosis Society of Canada. We thank Dr. Mario Moscarello (University of Toronto) for providing PLP, and Dr. Louis Flamand (Université Laval) for providing HHV-6 antigens.

\section{REFERENCES}

Arbour, N., Ekandé, S., Côté, G., Lachance, C., Chagnon, F., Tardieu, M., Cashman, N.R., and Talbot, P.J., 1999a, Persistent infection of human oligodendrocytic and neuroglial cell lines by human coronavirus 229E, J. Virol. 73:3326-3337.

Arbour, N., Côté, G., Lachance, C., Tardieu, M., Cashman, N.R., and Talbot, P.J., 1999b, Acute and persistent infection of human neural cell lines by human coronavirus OC43, $J$. Virol. 73:3338-3350.

Arbour, N., Day, R., Newcombe, J., and Talbot, P.J., 2000, Neuroinvasion by human respiratory coronaviruses, $J$. Virol., in press.

Bonavia, A., Arbour, N., Yong, V.W., and Talbot, P.J., 1997, Infection of primary cultures of human neural cells by human coronaviruses 229E and OC43, J. Virol. 71:800-806.

Burks, J.S., DeVald, B.L., Jankovsky, L.D., and Gerdes, J.C. (1980) Two coronaviruses isolated from central nervous system tissue of two multiple sclerosis patients, Science 209:933-934.

Challoner, P.B., Smith, K.T., Parker, J.D., Macleod, D.L., Coulter, S.N., Rose, T.M., Schultz, E.R., Bennett, J.L., Garber, R.L., Chang, M., Schad, P.A., Sewart, P.M., Nowinski, R.C., Brown, J.P., and Burmer, G.C., 1995, Plaque-associated expression of human herpesvirus 6 in multiple sclerosis, Proc. Natl Acad. Sci. USA 92:7440-7444.

Collins, A.R., and Sorensen, O., 1986, Regulation of viral persistence in human glioblastoma and rhabdomyosarcoma cells infected with coronavirus OC43, Microb. Pathog. 6:573-82.

Ebers, G.C., and Sadovnick, A.D., 1993, The role of genetic factors in multiple sclerosis susceptibility, J. Neuroimmunol. 54:1-17.

Lane, T.E., and Buchmeier, M.J., 1997, Murine coronavirus infection : a paradigm for virusinduced demyelinating disease, Trends Microbiol. 5:9-14.

Murray, R.S., Brown, B., Brian, D., and Cabirac, G.F., 1992, Detection of coronavirus RNA and antigen in multiple sclerosis brain, Ann. Neurol. 31:525-533.

Oldstone M.B.A., 1987, Molecular mimicry and autoimmune disease, Cell 50:819-820.

Sadovnick, A.D., Armstrong, H., Rice, G.P., Bulman, D., Hashimoto, L., Paty, D.W., Warren, S., Hader, W., Murray T.J., et al., 1993, A population-based study of multiple sclerosis in twins: update, Ann. Neurol. 33:281-285.

Stewart, J.N., Mounir, S., and Talbot, P.J., 1992, Human coronavirus gene expression in the brains of multiple sclerosis patients, Virology 191: 502-505. 
Talbot, P.J., Paquette, J.-S., Ciurli, C., Antel, J.P., and Ouellet, F., 1996, Myelin basic protein and human coronavirus $229 \mathrm{E}$ cross-reactive T cells in multiple sclerosis, Ann. Neurol. 39:233-240.

Watanabe, R., Wege, H., and ter Meulen, V., 1983, Adoptive transfer of EAE-like lesions from rats with coronavirus-induced demyelinating encephalomyelitis, Nature 5930:150153.

Weiner, L.P., 1973, Pathogenesis of demyelination induced by a mouse hepatitis, Arch. Neurol. 5:298-303.

Wekerle, H., Kojima, K., Lannes-Vieira, J., Lassmann, H., and Linington, C., 1994, Animal models, Ann. Neurol. 36:S47-53.

Wucherpfennig, K.W., and Strominger, J.L., 1995, Molecular mimicry in T cell-mediated autoimmunity: viral peptides activate human $\mathrm{T}$ cell clones specific for myelin basic protein, Cell 80:695-705.

Zhao, Z.S., Granucci, F., Yeh, L., Schaffer, P.A., and Cantor, H., 1998, Molecular mimicry by herpes simplex virus-type 1: autoimmune disease after viral infection, Science 279:1344-1347. 